\title{
PERFORMANCE ANALYSIS OF A SINGLE-PHASE AC VOLTAGE CONTROLLER UNDER INDUCTION MOTOR LOAD
}

\author{
E.S. Oluwasogo ${ }^{1}$, I.K. Okakwu ${ }^{2}$ \\ ${ }^{1}$ Lecturer, Electrical and Computer Engineering, Kwara State University, Kwara, Nigeria \\ ${ }^{2}$ Power Engineer, LM Ericsson Nigeria, Institute
}

\begin{abstract}
An AC voltage controller is a device that is used to accomplish continuous variation of the rotor speed and rotational force, or torque of an electric motor and the major component of the device are two thyristors connected in an inverse-parallel manner. So, thyristors applications are now rapidly expanding in the field of industrial automation because they are found to consume very little power whenever they are employed to manipulate the flow of electric power. The performance characteristics of thyristorized inverse parallel controller (IPC) under a single-phase induction motor load are presented in this paper. The thyristorized IPC or AC voltage controller is chosen as a cheaper and easier to build controller for induction machines and many more applications such as; induction heating and dimmer. This could save installation and maintenance costs for industries where many variable speed drives are in use. The induction motor stator voltage control is achieved via phase angle control of the AC supply. Performance evaluation of the controller with the motor under different delay angles is demonstrated. Due to nonsinusoidal nature of the controller output voltage, the level of ripples and harmonic contents is studied. As a result of half-wave symmetry in the stator voltage, only odd harmonics is considered in the Fourier based analysis used to investigate the control limits of the controller. MATLAB 7.8 software has been used to simulate the system and its results are compared with the experimental results obtained the laboratory prototype which is found to correlate.
\end{abstract}

Keywords: Inverse-Parallel Controller (IPC), Delay Angle, Variable Speed Drive (VSD), and Induction Motor.

\section{INTRODUCTION}

Motion control is the backbone of automation system widely used in every section of industrial and commercial activities, the heart of this motion control is variable speed drives (VSDs). An induction motors (AC drives) are widely used VSDs as a result of its low maintenance cost while offering equal and often superior dynamic performance over their DC drives counterparts in all possible scales (Large, Medium and small) of motion control tasks such as production machine, industrial robots, proportional tasks in electric transit vehicles, electric elevators, pumps and similar.

With the radical converter technology, it is conspicuous that the speed control of an induction motor can be achieved by stator voltage control at constant frequency to match the required speed/torque at the various applications [1].

In this method, the stator voltage of the single-phase induction motor is controlled by a pair of anti-parallel thyristors (AC Voltage Controller) through "phase control" means (i.e. $180^{\circ}$ mutual phase difference of the firing pulses is adopted for the pulses). The anti-parallel thyristors are not limited to motor controls but widely embraced in other power applications such as induction heating, resistance welding, dimmer, wind turbines and HVDC transmission lines.

In this paper, the proposed system (induction motor and voltage controller) are considered as non-linear system.
Various techniques for controlling $\mathrm{AC}$ drives were investigated in the past [M. H. Rashid Power Electronics Handbook, 2001] and the AC voltage controller method identified for precise further study. Although the AC voltage controller seems to be simple and not new but some complex analysis are involved. Two major problems encountered in analyzing the demeanour of the controller by this method under induction motor load are:

1. Control limit resolution and

2. Harmonic distortion due to non-linearity of the system.

The control (upper and lower) limit of the controller is studied since the induction motor efficiency is affected by operating voltage. Though, motors are generally designed to operate at rated supply voltage with a plus/minus tolerance (10\% is typical). [2]

In this work, a novel single-phase AC Voltage scheme was designed to suppress the magnitude of lower order harmonics by using fewer semi-conductor devices in the power flow path to control the AC drive.[3] and [4]. The rest of this paper work is sectioned as; system modeling and analysis, simulation results and discussions, and conclusion.

\section{SYSTEM MODELING AND ANALYSIS}

Many researchers analyzed single-phase voltage controller under pure resistive( $\mathrm{R})$ and $\mathrm{R}-\mathrm{L}$ load to obtain mathematical expressions on load current and $r m s$ output voltage. This can 
be extended to induction motor by reducing the equivalent circuit of the induction motor to $\mathrm{R}_{\mathrm{eq}}$ and $\mathrm{L}_{\mathrm{eq}}$. [5]

In this research, a detailed analysis for single-phase induction motor by using double-field revolving theory is carried out to obtain equivalent circuit parameters such as load angle used in determining mode of operation and control limit of the controller. Then, a computer MATLAB program has been used to obtain performance parameters in terms of delay angle theoretically. Also, MATLAB simulation program (SIMULINK) was used to validate the designed model results obtained in laboratory.

The principal circuit of a single-phase induction motor fed by AC voltage controller comprises; 1- $\varphi$ AC source, a pair of anti-parallel thyristors and $1-\varphi$ asynchronous motor as shown in fig. 1.

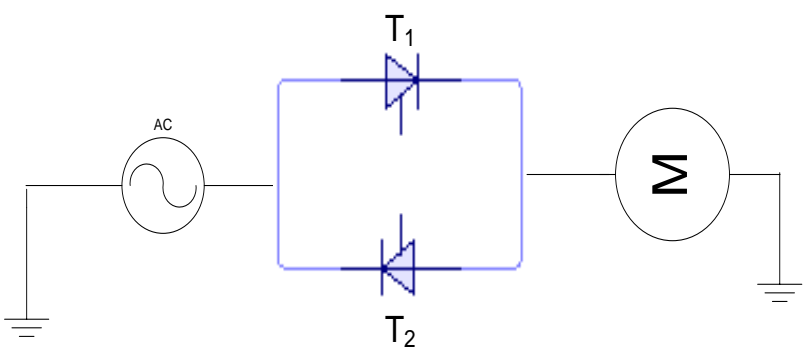

Fig -1: Single-Phase AC-AC Drive

\subsection{R-L Modeling of a Single-Phase Induction}

\section{Motor}

The electrical model for a single-phase induction motor is achieved by using model of a three-phase induction motor twice. The simplified equivalent circuit of the induction motor is given below under running condition. The singlephase motor is assumed to have; one stator winding, two rotor windings (double-field revolving theory) and lossless core. $[6$

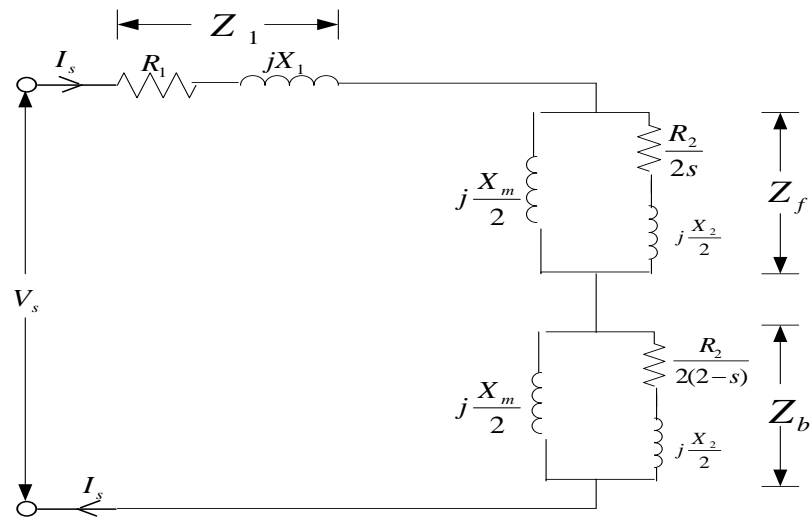

Fig -2: Equivalent circuit of single phase induction motor (at rotor running condition)
Let;

$\mathrm{R}_{1}=$ Resistance of stator winding

$\mathrm{X}_{1}=$ Leakage reactance of stator winding

$\mathrm{X}_{\mathrm{m}}=$ Total magnetizing reactance

$\mathrm{R}_{2}=$ Resistance of the rotor referred to the stator

$\mathrm{X}_{2}=$ Leakage reactance of the rotor referred to the stator $\mathrm{s}=$ Motor slip

$\mathrm{V}_{\mathrm{m}}=$ Peak value of the input voltage $=\sqrt{2} V_{s}$

If: $\mathrm{x}_{\mathrm{m}}, \mathrm{r}_{2}$, and $\mathrm{x}_{2}$ represents half value of; magnetizing reactance, rotor resistance and rotor reactance respectively. Then;

The expression for stator impedance is:

$$
Z_{1}=R_{1}+j X_{1}
$$

The referred rotor impedance due to forward field is given as:

$$
Z_{f}=\frac{j x_{m}\left(\frac{r_{2}}{s}+j x_{2}\right)}{\frac{r_{2}}{s}+j\left(x_{m}+x_{2}\right)}
$$

The referred rotor impedance due to backward field is expressed as:

$$
Z_{b}=\frac{j x_{m}\left(\frac{r_{2}}{2-s}+j x_{2}\right)}{\frac{r_{2}}{2-s}+j\left(x_{m}+x_{2}\right)}
$$

Assuming;

$$
x_{d}=x_{m}+x_{2} ; \quad P=\left(\frac{r_{2}}{s}\right)^{2}+\left(x_{d}\right)^{2} \text { and } \quad Q=\left(\frac{r_{2}}{2-s}\right)^{2}+\left(x_{d}\right)^{2}
$$

The equivalent impedance $\mathrm{Z}_{\mathrm{eq}}$ can be express as shown in (4),

$$
Z_{e q}=Z_{1}+Z_{f}+Z_{b}
$$

This can be simplified further to equivalent; resistance $R_{\text {eq }}$, inductance $\mathrm{L}_{\mathrm{eq}}$ and load angle (power factor angle) $\varphi$ as shown in (5).

$$
Z_{e q}=R_{e q}+j X_{e q}=\sqrt{\left(R_{e q}^{2}+X_{e q}^{2}\right)} \angle \phi
$$

Where; 


$$
\begin{aligned}
& R_{e q}=R_{1}+x_{m}^{2}\left(\frac{r_{2} / s}{P}+\frac{r_{2} /(2-s)}{Q}\right) \\
& X_{e q}=X_{1}+x_{m}\left(\frac{\left(\frac{\left.r_{2} / s\right)^{2}+x_{2} x_{d}}{P}+\frac{\left(r_{2} /(2-s)\right)^{2}+x_{2} x_{d}}{Q}\right)}{Q}\right) \\
& \Rightarrow \quad \mathrm{L}_{\mathrm{eq}}=\frac{X_{e q}}{2 \pi f}
\end{aligned}
$$

And

$$
\phi=\tan ^{-1}\left(\frac{X_{e q}}{R_{e q}}\right)
$$

Now the equivalent parameters of the motor is known, the single-phase control circuit with the motor can be represented by two SCR's connected back-to-back with R-L as shown in Fig. 3.

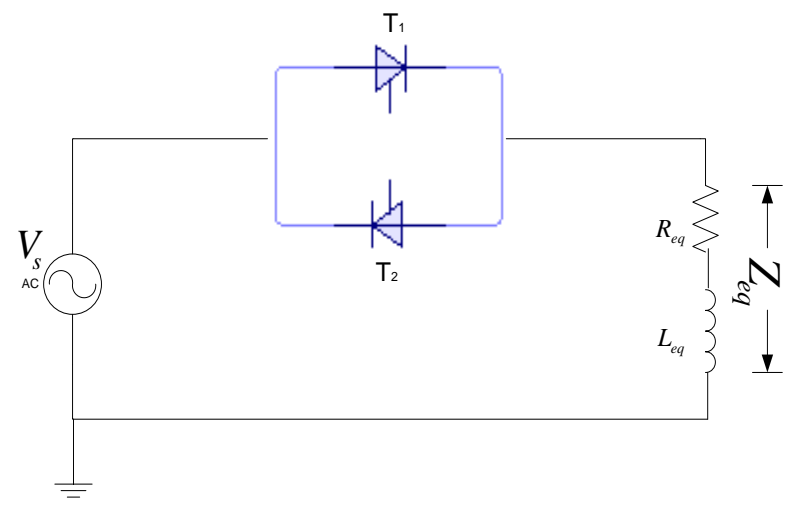

Fig-3: R-L Equivalent Circuit of the Single-Phase AC-AC Drive Model

Thyristor $\mathrm{T}_{1}$ conducts during positive half cycle of the supply voltage and thyristor $\mathrm{T}_{2}$ conduct for negative half cycle of the supply voltage. Due to inductance in the load, $\mathrm{T}_{1}$ will conduct from $\omega t=\alpha$ till when all energy stored in the load inductor is completely utilized at $\omega t=\pi+\phi=\beta$ (Extinction angle) as seen in fig.4.

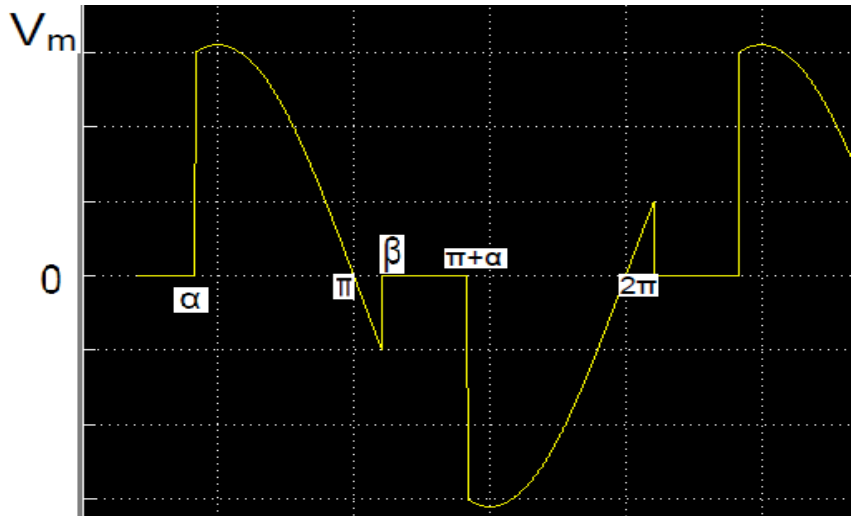

Fig-4: Thyristors Output Voltage Waveform across R-L Load

The analysis and extent of switching for a single-phase ac voltage controller under induction motor $(\mathrm{R}-\mathrm{L})$ load depends on the relative values of firing $(\alpha)$ and load $(\varphi)$ angles which gives three modes of operation summarized as:

Mode1/2: $\quad(\boldsymbol{0}<\boldsymbol{\alpha}<\boldsymbol{\varphi})$; Only thyristor $\mathrm{T}_{1}$ conducts for positive half cycle, the conduction beyond $\pi$ is a result of inductance current flowing through the load due to energy stored in the inductor load.

Mode 2/2: $\quad(\boldsymbol{\varphi}<\boldsymbol{\alpha}<\boldsymbol{\pi})$; thyristors $\mathrm{T}_{1}$ and $\mathrm{T}_{2}$ conducts for positive and negative half cycle respectively. The rms voltage at stator of the induction motor with $\mathrm{AC}$ voltage controller operating in this mode is given by:

$$
\begin{aligned}
& V_{o(R M S)}=\left[\frac{1}{\pi} \int_{\alpha}^{\beta} V_{m}^{2} \sin ^{2} \omega t d(\omega t)\right]^{1 / 2} \\
& V_{o(R M S)}=\frac{V_{m}}{\sqrt{2}}\left[\frac{1}{\pi}\left\langle\beta-\alpha+\frac{\sin 2 \alpha}{2}-\frac{\sin 2 \beta}{2}\right\rangle\right]^{1 / 2}
\end{aligned}
$$

Mode 0/2: $\quad \boldsymbol{a} \geq \pi ; \quad$ none of the thyristors conduct and zero output is obtained.

\subsection{Total Harmonic Distortion Analysis of the}

\section{Controller}

Due to non-linearity behaviour of the controller and the load, the output voltage is non-sinusoidal i.e. distorted. This distortion in the voltage output waveform is called Voltage Harmonic Distortion which is analyzed using Fourier analysis of the explicit expressions for the instantaneous output voltage over a period of the voltage waveform as follows:

$$
V(\omega t)=\sum_{n=2}^{\infty}\left(A_{n} \cos n \omega t+B_{n} \sin n \omega t\right)
$$

Where the coefficients $A_{n}$ and $B_{n}$ are expressed as: 
$A_{n}=\frac{1}{T} \int_{0}^{T} V(\omega t) \cos n \omega t d(\omega t)$

$B_{n}=\frac{1}{T} \int_{0}^{T} V(\omega t) \sin n \omega t d(\omega t)$.

$T$ is the period

$A_{n}$ and $B_{n}$ are the Maximum value of the sine and cosine components of the harmonics of order $n$; present in the output voltage waveform respectively.

If the amplitude (maximum value) and the phase angle of the $n^{\text {th }}$ harmonic component are $C_{n}$ and $\theta_{n}$ respectively which are define as:

$$
\begin{aligned}
& C_{n}=\sqrt{A_{n}+B_{n}} \\
& \theta_{n}=\tan ^{-1}\left(\frac{B_{n}}{A_{n}}\right)
\end{aligned}
$$

The instantaneous output voltage $V_{O}(\omega t)$ of the AC-Voltage controller operating at mode $2 / 2(\alpha>\varphi)$ is defined analytically as given in table 1:

\begin{tabular}{|c|c|c|}
\hline S/No & $\begin{array}{ll}\text { Instantaneous } & \mathrm{O} / \mathrm{P} \\
\text { Voltage } V_{O}(\omega t) & \\
\end{array}$ & Conduction Interval \\
\hline 1. & 0 & $0<\omega t<\alpha$ \\
\hline 2. & $V_{m} \sin \omega t$ & $\alpha<\omega t<\pi+\varphi$ \\
\hline 3. & 0 & $\pi+\varphi<\omega t<\pi+\alpha$ \\
\hline 4. & $V_{m} \sin \omega t$ & $\pi+\alpha<\omega t<2 \pi+\varphi$ \\
\hline
\end{tabular}

Table -1: Instantaneous Controller Voltage

Only the odd harmonics are present in output voltage because of the half-wave symmetry

Harmonic components derived for different intervals of operation are:

$$
\begin{aligned}
& A_{n}=\frac{V_{m}}{\pi}\left[\frac{1}{n+1}\{\cos (n+1) \alpha-\cos (n+1) \phi\}-\frac{1}{n-1}\{\cos (n-1) \alpha-\cos (n-1) \phi\}\right] . \\
& B_{n}=\frac{V_{m}}{\pi}\left[\frac{1}{n+1}\{\sin (n+1) \alpha-\sin (n+1) \phi\}-\frac{1}{n-1}\{\sin (n-1) \alpha-\sin (n-1) \phi\}\right] .
\end{aligned}
$$

If $\varphi=0^{\mathrm{O}}$; similar to pure resistive load:

The $R M S$ value of the $\mathrm{n}^{\text {th }}$ harmonic component is:

$$
V_{n(R M S)}=\frac{C_{n}}{\sqrt{2}}=\frac{\sqrt{A_{n}^{2}+B_{n}^{2}}}{\sqrt{2}}=\sqrt{\frac{A_{n}^{2}+B_{n}^{2}}{2}}
$$

$$
\begin{aligned}
& A_{n}=\frac{V_{m}}{\pi}\left[\frac{1}{n+1}\{\cos (n+1) \alpha-1\}-\frac{1}{n-1}\{\cos (n-1) \alpha-1\}\right] \\
& B_{n}=\frac{V_{m}}{\pi}\left[\frac{1}{n+1}\{\sin (n+1) \alpha\}-\frac{1}{n-1}\{\sin (n-1) \alpha\}\right]
\end{aligned}
$$

\section{Sample Motor Data}

The operating characteristics parameters of a single phase induction motor from the laboratory is shown in Table 2

Table -2: The AC Motor Parameters Used

\begin{tabular}{|l|l|l|}
\hline Quantity & Symbol & In actual unit \\
\hline Rated Voltage & $\mathrm{V}_{\mathrm{s}}$ & $220 \mathrm{~V}$ \\
\hline Supply frequency & $F$ & $50 \mathrm{~Hz}$ \\
\hline Line Current & $\mathrm{I}_{1}$ & $2.5 \mathrm{~A}$ \\
\hline Speed & $\mathrm{N}$ & $1440 \mathrm{RPM}$ \\
\hline Number of poles & $\mathrm{P}$ & 4 \\
\hline $\begin{array}{l}\text { Stator Winding } \\
\text { Resistance }\end{array}$ & $\mathrm{R}_{1}$ & $2.02 \Omega$ \\
\hline $\begin{array}{l}\text { Stator Winding } \\
\text { Reactance }\end{array}$ & $\mathrm{X}_{1}$ & $2.32 \Omega$ \\
\hline $\begin{array}{l}\text { Magnetizing } \\
\text { Reactance }\end{array}$ & $\mathrm{X}_{\mathrm{m}}$ & $55.67 \Omega$ \\
\hline $\begin{array}{l}\text { Rotor Referred } \\
\text { Resistance }\end{array}$ & $\mathrm{R}_{2}$ & $4.12 \Omega$ \\
\hline $\begin{array}{l}\text { Rotor } \\
\text { Reactance }\end{array}$ & $\mathrm{X}_{2}$ & $1.76 \Omega$ \\
\hline
\end{tabular}

$\Phi=58.67^{\mathrm{O}}$

\subsection{MATLAB Computer Simulation}

The simulation of single-phase voltage control under induction motor (R-L) load was carried out by five major circuit element blocks: AC voltage supply, Thyristors $\left(\mathrm{T}_{1}\right.$ and $\left.\mathrm{T}_{2}\right)$, pulse generators ( $\mathrm{PG} \mathrm{T}_{1}$ and $\left.\mathrm{PG} \mathrm{T}_{2}\right)$, Resistor $\left(\mathrm{R}_{\mathrm{eq}}\right)$ and Inductor $\left(\mathrm{L}_{\mathrm{eq}}\right)$. Simulation was done for different firing angles $(\alpha)$ i.e. delay time $(t)$ to determine the control limits of the drive. MATLAB m-file code was developed to obtain values for; $R_{e q}, L_{e q}, \varphi$, and harmonic amplitudes $C_{n}$ based on equations (1) to (20) from the motor manufacturer nameplate shown in Table 2.

\section{Pulse Generator Delay Time}

Since pulse generator is a time-based selector, the firing angle $(\alpha)$ was converted to time-based delay as calculated in eqn (18) below. The pulse period (T) is the same as the period of AC supply voltage. For a system of $50 \mathrm{~Hz}$ $(T=1 / f=1 / 50 s)=(20 \mathrm{~ms}) \cdot[4]$

Since delay angle is expressed as;

$$
\begin{gathered}
\alpha=\omega t \\
\therefore t=\frac{\alpha(\mathrm{rad})}{\omega(\mathrm{rad} / \mathrm{s})}=\frac{\alpha}{2 \pi f} \quad \text { in seconds }
\end{gathered}
$$


In this paper, harmonics analysis have been achieved using a MATLAB programs; SIMULINK/FFT tool and m-file to obtain graphical results of THD and Instantaneous Harmonics Voltage Amplitude as seen in Fig. 9 and Fig. 12, Fig. 13 respectively.

\section{RESULTS}

Both the simulation and the laboratory tests were done under the three (3) modes. The simulation results are shown in Fig. 5 to Fig. 8, while Fig. 14 and Fig. 15 shows the experimentation signals as seen on the oscilloscope in the laboratory.

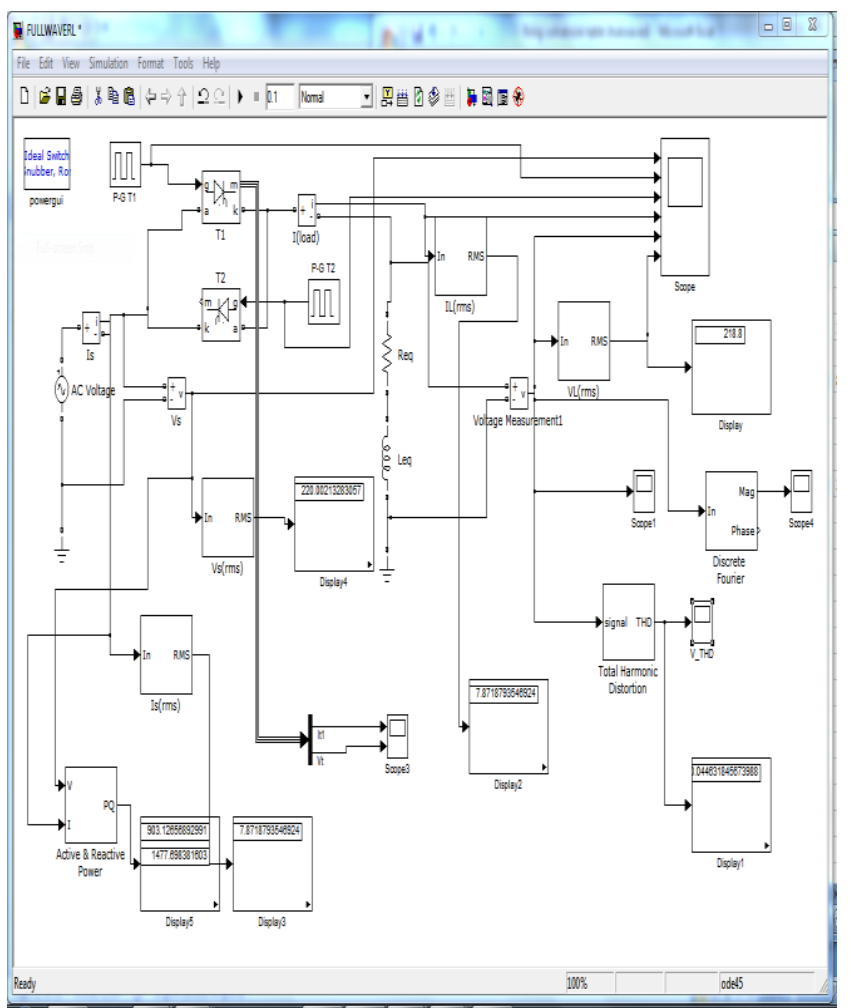

Fig-5: Simulated Model of Back-To- Back Thyristors Controller Feeding R-L Load

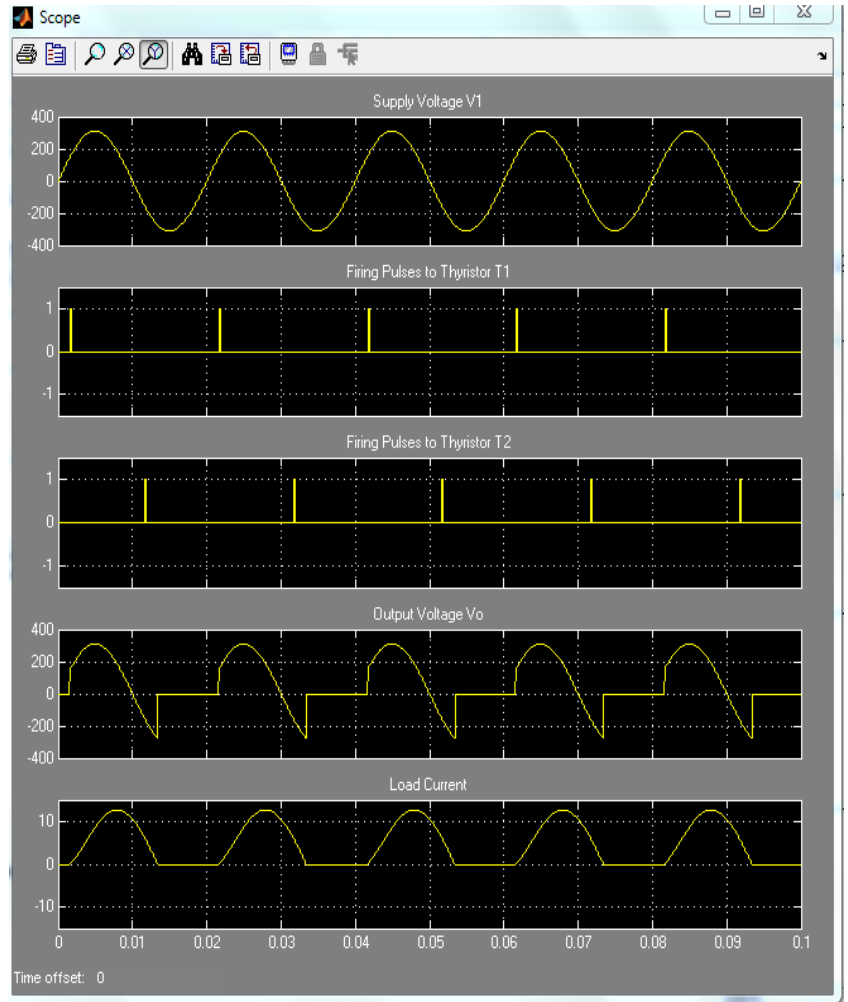

Fig-6: Simulation Waveforms of the Controller at $\alpha=30^{\circ}$ (Mode 1/2)

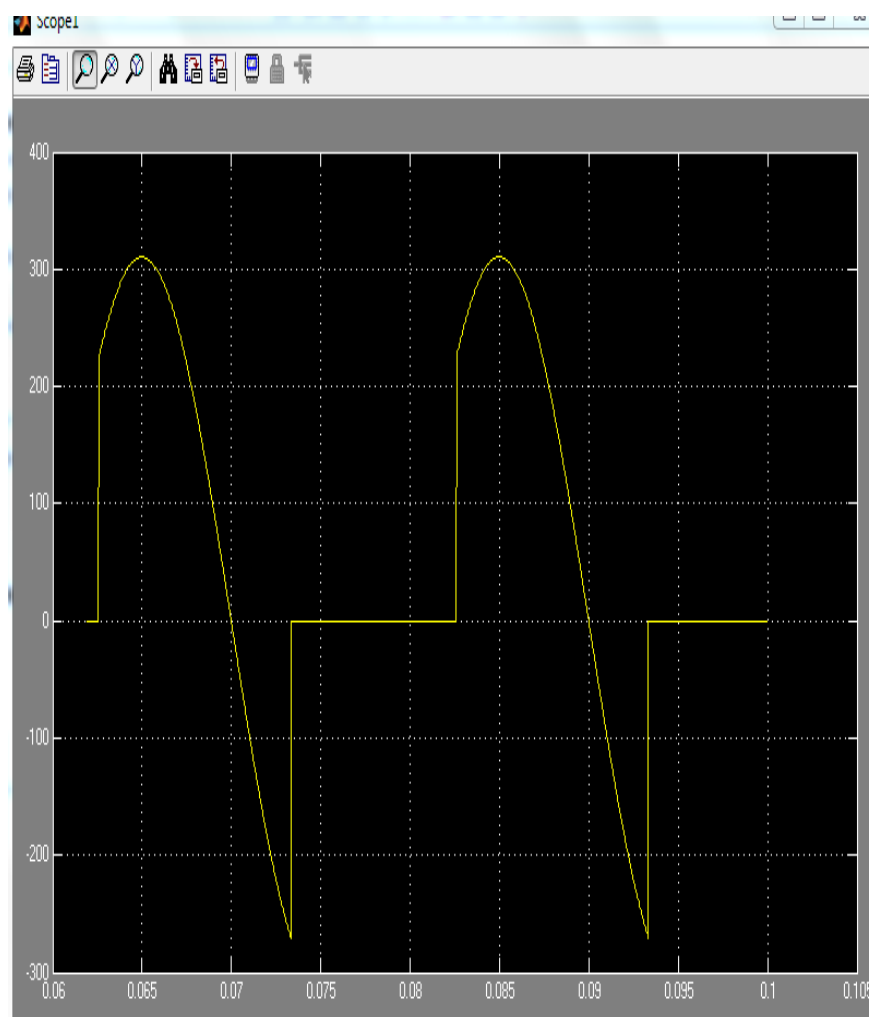

Fig-7: Output Voltage Signal at $\alpha=45^{\circ}$ Mode $1 / 2$ 


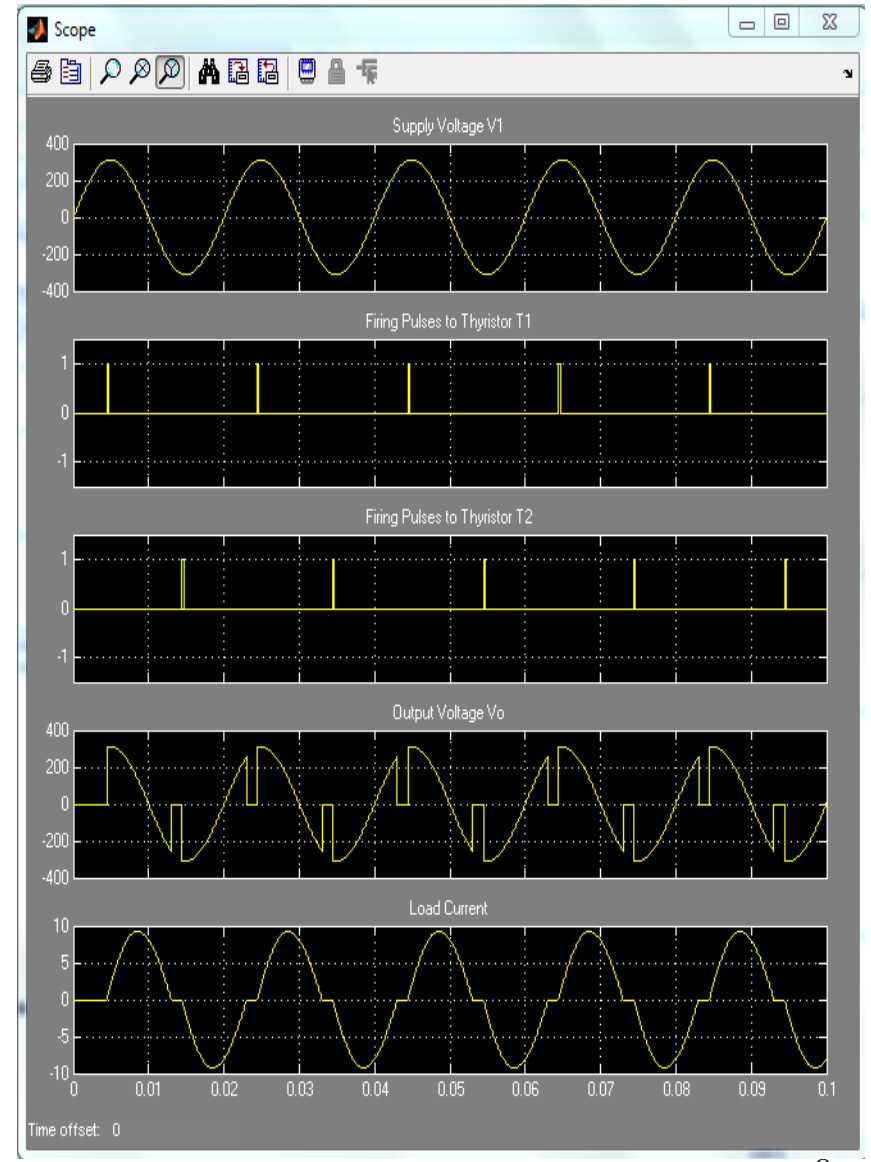

Fig-8: Simulation Waveforms of the Controller at $\alpha=80^{\circ}$ (Mode 2/2)

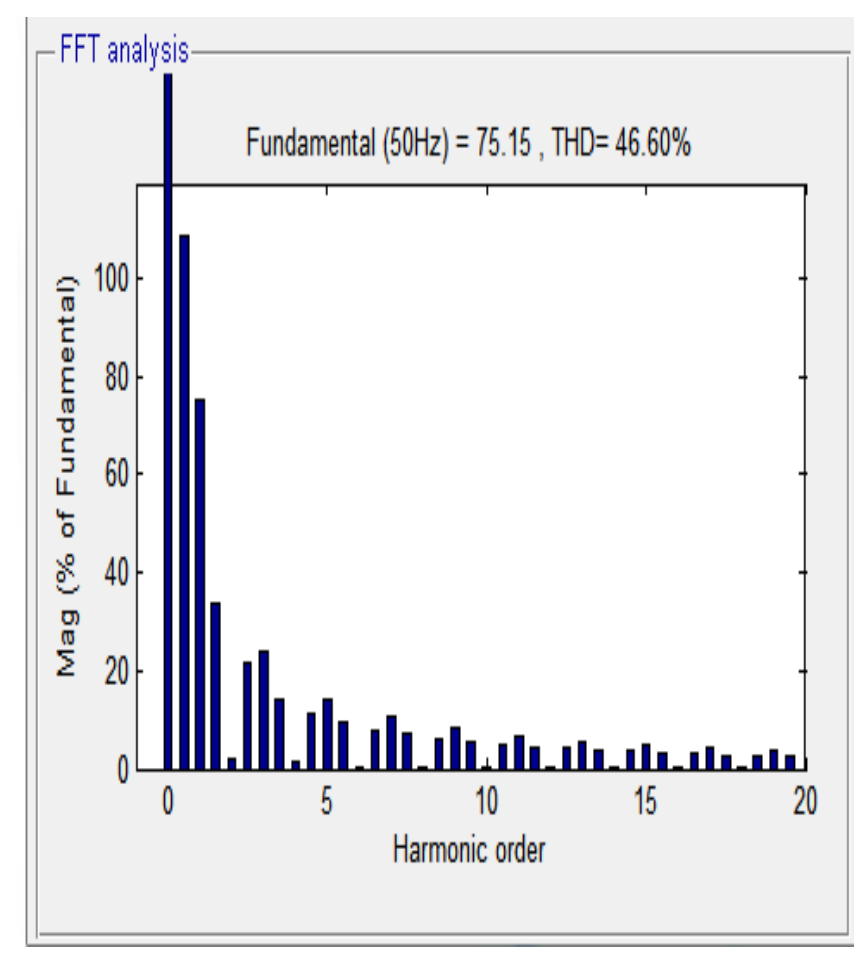

Fig.-9: Harmonics Spectrum of the Controller at a Delay Angle $\alpha=80^{\circ}$

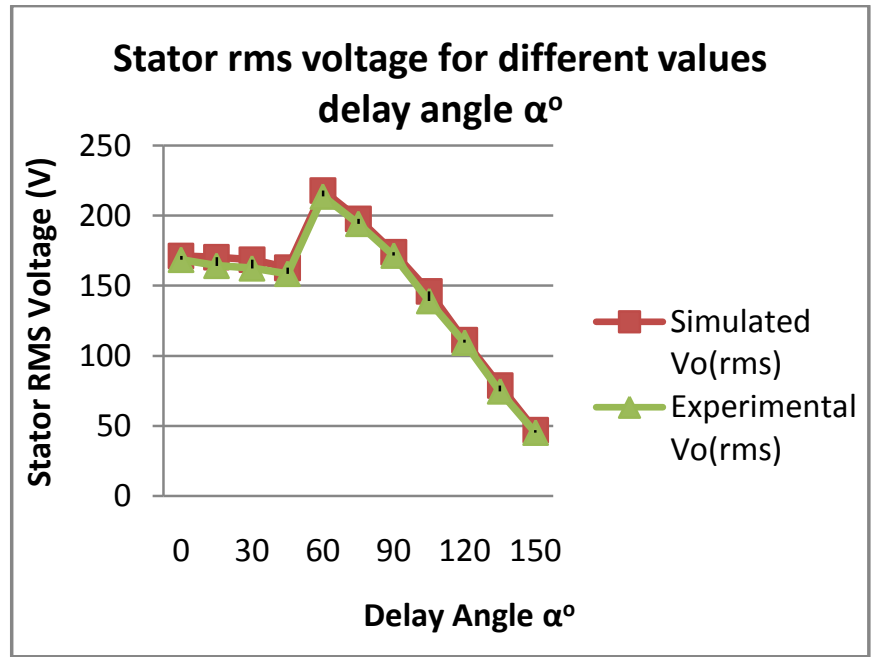

Fig-10: Variation of Stator rms Voltage with different Delay Angle

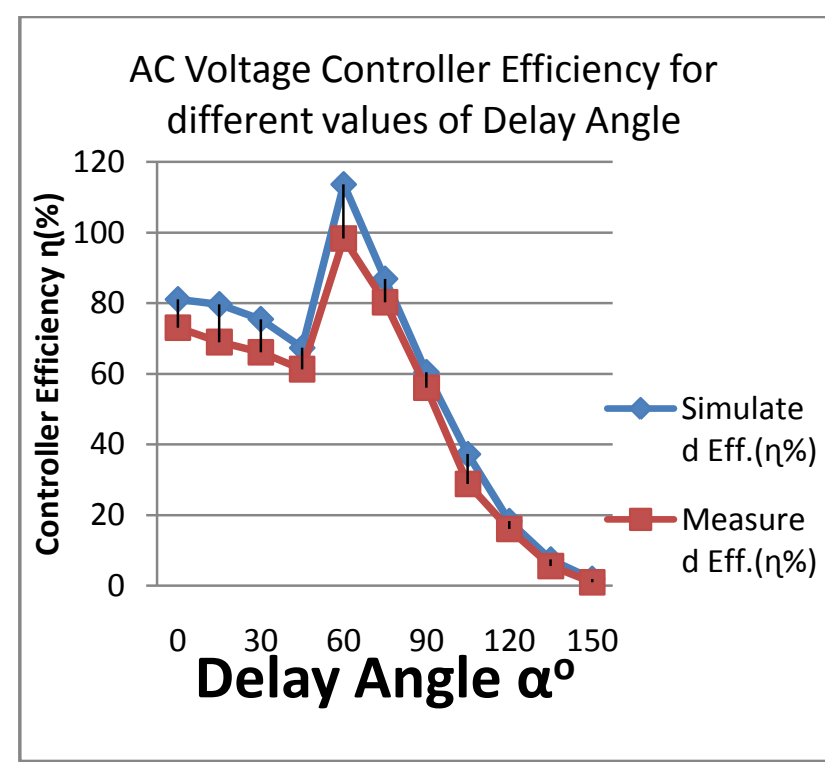

Fig-11: Controller Efficiency for different Delay Angle

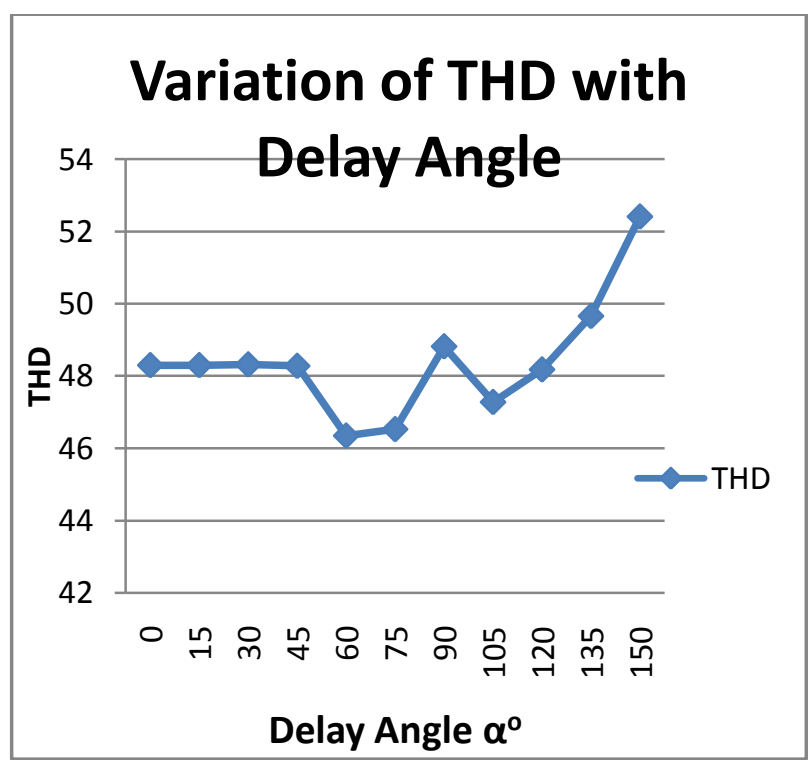

Fig-12: Variation of THD with Delay Angle 


\section{Variation of Harmonic Voltage with Delay Angle}

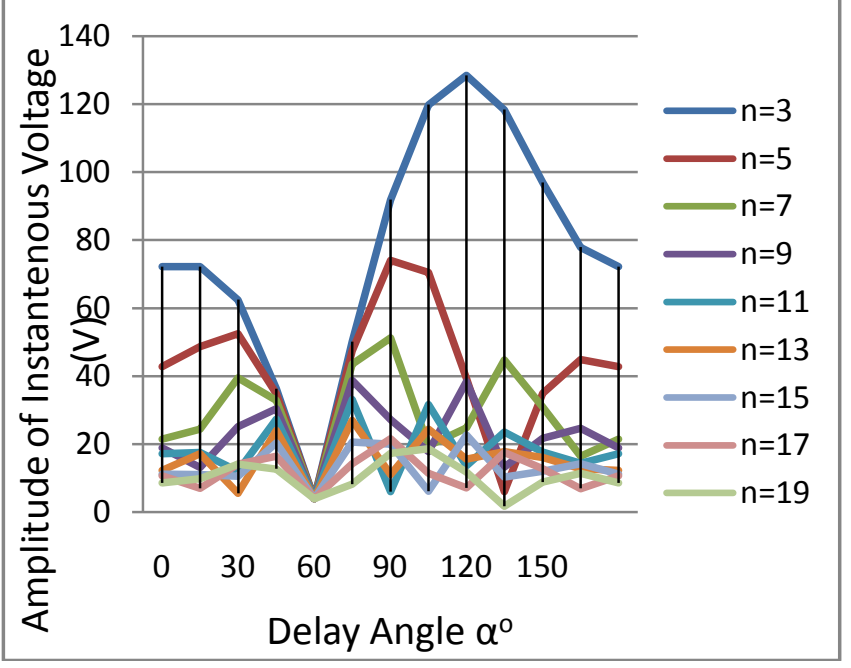

Fig-13: Variation of Harmonic Voltage with Delay Angle

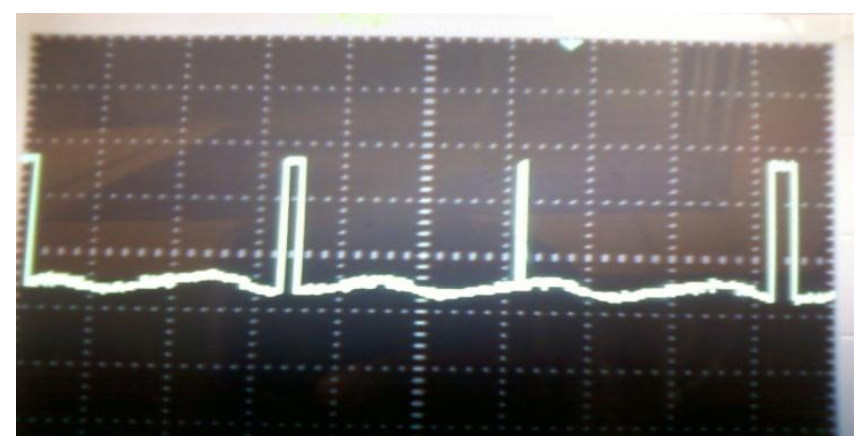

Fig. 14 Implemented gate signal

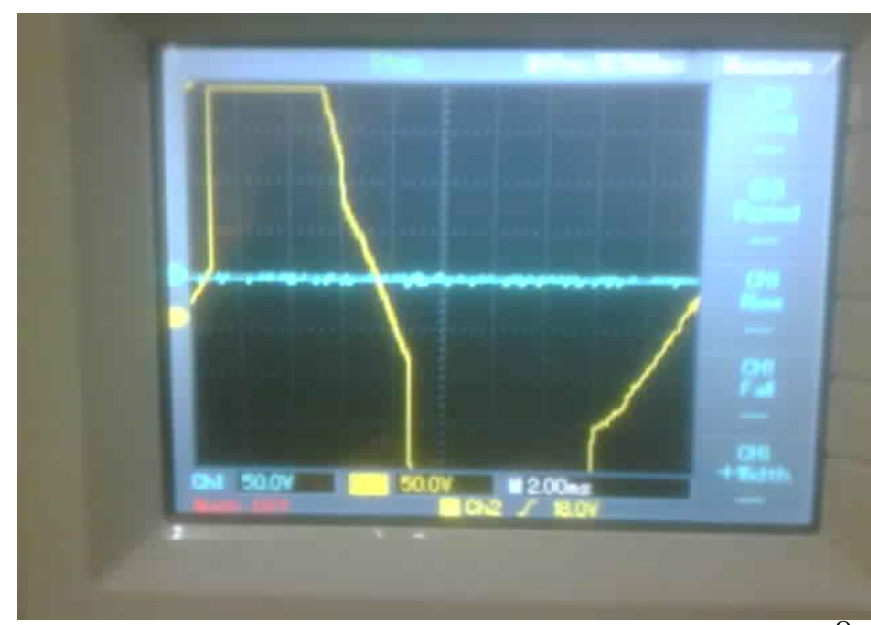

Fig-15: Stator Voltage seen on the oscilloscope at $\alpha=\varphi=58^{\mathrm{O}}$

\section{DISCUSSION OF RESULTS}

The performance characteristics resulting from AC Voltage control technique are shown in Figs. (6) to (15). From Fig. 10 and Fig. 11 showing convenient results comparison of the simulated (theoretical) and implemented (experimental) controller behaviour, It can be deduced that AC Voltage controller is appropriate for the control of an induction drives . Also, it is obvious that only thyristor $\mathrm{T}_{1}$ conducts for mode $1 / 2$ while, thyristors $T_{1}$ and $T_{2}$ conducts for mode $2 / 2$.

The variation of stator voltage with delay angle is shown in Fig 10. It is clear that the stator voltage is almost linear for the controller operating in the mode $1 / 2$ region whereas; the stator voltage is inversely proportional to the delay angle in mode $2 / 2$. So, it is necessary the controller identify the mode of operation from the load characteristic before sending firing pulses at appropriate delay time to the SCRs or else control would be lost.

The result obtained in Fig. 12, show the variation of THD with delay angle for the sample induction motor, it has been observed that THD is low and directly proportional to delay angle for mode $2 / 2$ except for the regions near mode $0 / 2$ where it is very high due to high ripple contents in the load current.

The variations of the harmonic spectrum of the stator voltage with the order of harmonic and delay angle are shown in Figs. 9 and 13 respectively. It is clear that only odd harmonics are presents in the controlled voltage (Fig.9). From Fig. 13, it is patent that the magnitude of the voltage harmonic content is zero at the boundary between modes $1 / 2$ and $2 / 2$ (i.e. pure sinusoidal is obtained at delay angle equal load angle) and increases with delay angle elsewhere.

\section{CONCLUSIONS}

This work primarily focuses on proposing an efficient and portable controller for an induction motor at a low cost implication. The results from implemented controller and that of MATLAB SIMULINK were seen to correlate. The control of the induction motor is achieved through the control of the firing pulses. By increasing the delay time of these pulses to SCRs, the stator voltage is decreased or vice versa. It is essential the controller identify the exact boundary region for the modes of operation from the load characteristics. Since the performance (i.e. extent of control, efficiency and THD) of the controller is best at mode $2 / 2$. It is concluded that a single-phase AC voltage controller should be impel to work in this mode. Therefore, the extents of control largely depends on the load angle

\section{REFERENCES}

[1] Malcolm B. Practical Variable Speed Drives and Power Electronics. Newness 2003 IDC Technologies Pg1

[2] Fan Engineering "Single-Phase Ac Induction Squirrel Cage Motors" Information and Recommendations for the Engineer. FE-1100

[3] C.C. Okoro, et. al. "Correction Of Input Power Factor Problem In Industrial Drives" IET Int. Conf., 2011

[4] E.S. Oluwasogo, "Design and Implementation of a $2 \mathrm{~kW}$ Inverse-Parallel Controller for Three-Phase Induction Motor" M.Sc Thesis (2012), University of Lagos. 
[5] A.I. Alolah, et. al. Control Limits of Three-Phase AC Voltage Controller under Induction Motor Load www.researchgate.net

[6] V.K. Mehta, Rohit Mehta "Principle of Electrical Machines" S. Chand, 2002. PP 240 - 242.

\section{BIOGRAPHIES}

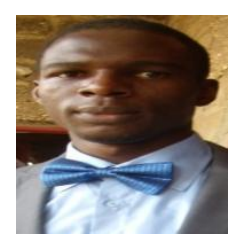

E.S. Oluwasogo graduated from University of Ilorin, Nigeria, in 2008. He received the M.Sc degree from the University of Lagos, Nigeia, all in Electrical Engineering. He is a lecturer in the Department of Electrical \& Computer

Engineering at Kwara State University, Malete, Nigeria. His research interests include Control of Industrial drives, Distribute Systems Control, Optimization and Robust Control, Automation etc. He is a member of IEEE and a registered Engineer with COREN.

I.K. Okakwu graduated from Ambrose Alli University, Ekpoma (Nigeria) in 2008. He received M.sc degree from the University of Lagos in 2012 all in Electrical/Electronics Engineering. $\mathrm{He}$ is currently pursuing a $\mathrm{PhD}$ degree in

Electrical / Electronics Engineering, University of Benin, Nigeria. His area of interest include power systems stability and control, electrical machines, power systems reliability, economic dispatch, FACTS and its applications, Deregulation 